\title{
Niemann-Pick disease type C: a case series of Brazilian patients
}

\author{
Doença de Niemann-Pick tipo C: série de casos de pacientes brasileiros \\ Paulo José Lorenzoni', Elaine Cardoso ${ }^{1}$, Ana C. S. Crippa ${ }^{1}$, Charles Marques Lourenço², \\ Fernanda Timm Seabra Souza ${ }^{3}$, Roberto Giugliani, ${ }^{3,4}$, Maria Luiza Saraiva-Pereira ${ }^{3,5}$, Salmo Raskin ${ }^{1}$, \\ Isac Bruck', Cláudia S. K. Kay , Rosana H. Scola ${ }^{1}$, Lineu C.Werneck , Hélio A. G. Teive ${ }^{1}$
}

\begin{abstract}
The aim of the study was to analyze a series of Brazilian patients with Niemann-Pick disease type C (NP-C). Method: Correlations between clinical findings, laboratory data, molecular findings and treatment response are presented. Result: The sample consisted of 5 patients aged 8 to 26 years. Vertical supranuclear gaze palsy, cerebellar ataxia, dementia, dystonia and dysarthria were present in all cases. Filipin staining showed the "classical" pattern in two patients and a "variant" pattern in three patients. Molecular analysis found mutations in the NPC1 gene in all alleles. Miglustat treatment was administered to 4 patients. Conclusion: Although filipin staining should be used to confirm the diagnosis, bone marrow sea-blue histiocytes often help to diagnosis of NP-C. The p.P1007A mutation seems to be correlated with the "variant" pattern in filipin staining. Miglustat treatment response seems to be correlated with the age at disease onset and disability scale score at diagnosis.
\end{abstract}

Keywords: Niemann-Pick disease type C, bone marrow, filipin stain, NPC1gene, miglustat.

RESUMO

O objetivo desse estudo foi analisar uma série de casos de pacientes brasileiros com doença de Niemann-Pick tipo C (NP-C). Método: Correlação entre manifestações clínicas, alterações laboratoriais, estudo molecular e resposta ao tratamento foram realizadas. Resultado: A amostra consiste de 5 pacientes com idade entre 8 e 26 anos. Paralisia do olhar vertical supranuclear, ataxia cerebelar, demência, distonia e disartria estavam presentes em todos os casos. Coloração de filipina na cultura de fibroblastos mostrou padrão "clássico" em dois pacientes e padrão "variante" em três casos. O estudo molecular encontrou mutações no gene NPC1 em todos os alelos. O tratamento com miglustate foi realizado em 4 pacientes. Conclusão: Embora coloração de filipina seja utilizada para confirmar o diagnóstico, o histiócito azul-marinho no aspirado de medula óssea frequentemente auxilia a confirmar o diagnóstico de NP-C. A mutação p.P1007A está correlacionada com o padrão "variante” na coloração de filipina. A resposta ao tratamento com miglustate parece estar correlacionada com a idade e escore de desabilidade no momento do diagnóstico.

Palavras-chave: doença de Niemann-Pick tipo C, medula óssea, coloração de filipina, gene NPC1, miglustate.

Niemann-Pick disease type C (NP-C) is a rare inherited disease, caused by mutations in either the $N P C 1$ or the $N P C 2$ gene, which leads to impaired intracellular lipid trafficking and the accumulation of cholesterol and glycosphingolipids in the brain and other tissues ${ }^{1-6}$. The clinical signs and symptoms of NP-C can develop at any age, and significant phenotypic heterogeneity is frequently observed in NP$\mathrm{C}^{1,2,47}$. Vertical supranuclear gaze palsy, cerebellar ataxia, dystonia, dementia, epilepsy and visceral manifestations are the most common symptoms of NP-C $\mathrm{C}^{1,2,4-7}$.

NP-C patients often show sea-blue histiocytes or foamy cells in bone marrow analyses and intracellular lipid accumulation with filipin staining ${ }^{1,3,4,6,7}$. Molecular analyses typically show $N P C 1$ (in $95 \%$ of cases) or NPC2 (in around $4 \%$ of cases) gene mutations ${ }^{1-4,6,7}$. Nevertheless, vertical supranuclear gaze palsy, cataplexia, high chitotriosidase serum

\footnotetext{
${ }^{1}$ Serviço de Neurologia, Departamento de Clínica Médica, Universidade Federal do Paraná, Curitiba PR, Brazil;

${ }^{2}$ Departamento de Genética, Faculdade de Medicina de Ribeirão Preto, Universidade de São Paulo, Ribeirao Preto SP, Brazil;

${ }^{3}$ Serviço de Genética Médica, Hospital de Clínicas de Porto Alegre, Porto Alegre RS, Brazil;

${ }^{4}$ Departamento de Genética, Universidade Federal do Rio Grande do Sul, Porto Alegre RS, Brazil;

${ }_{5}^{5}$ Departamento de Bioquímica, Universidade Federal do Rio Grande do Sul, Porto Alegre RS, Brazil.

Correspondence: Hélio A. G. Teive; Serviço de Neurologia, Hospital de Clínicas da Universidade Federal do Paraná; Rua General Carneiro 181 / $4^{\circ}$ andar; 80060-900 Curitiba PR - Brasil; E-mail: teiveads@mps.com.br

Conflict of interest: There is no conflict of interest to declare.

Received 24 September 2013; Received in final form 05 November 2013; Accepted 26 November 2013.
} 
level and relatives with similar symptoms are also considered to be clinical clues pointing to the diagnosis ${ }^{4-7}$.

In this study, we analyzed clinical manifestations, disease progression, brain imaging, laboratory features, intracellular lipid accumulation and molecular findings from 5 patients with NP-C to contribute to the better characterization of this disease in Brazil.

\section{METHOD}

A retrospective analysis of five patients with NP-C, diagnosed between January 2005 and January 2013, was performed based on the following features: typical clinical manifestations; foamy cells or sea-blue histiocytes cell in the bone marrow; or abnormal intracellular lipid accumulation observed with filipin staining. Informed consent for laboratory and molecular analyses were obtained from all of the patients (in the outpatient clinic or during hospital admission for diagnostic investigation in the Hospital de Clínicas da Universidade Federal do Paraná).

\section{Clinical evaluation}

Relevant data were collected, including age, gender, neurological and visceral manifestations, clinical evaluation, and the presence of other affected relatives. The clinical presentation was categorized according to the patient's age at onset of the disease as follows: neonatal (onset at age $\leq 3$ months), early infantile (onset at age 3 months to 2 years), late infantile (onset at age 2 to $<6$ years), juvenile (onset at age 6 to 15 years) or adult (onset at age $>15$ years). The NP-C-specific disability scale was used to evaluate the severity of the disease ${ }^{3}$. Patient response to substrate reduction therapy with miglustat was classified as present, absent, or partial based upon the objective improvements in clinical manifestations and the scores on the NP-C-specific disability scale over the course of the drug treatment (after at least 1 year of use).

\section{Brain images}

Radiologic findings from brain magnetic resonance imaging (MRI) were also reported.

\section{Laboratory analysis}

Chitotriosidase levels in patient serum samples were measured (normal range: 8.8 - $132.0 \mathrm{nmol} / \mathrm{h} / \mathrm{ml}$ ).

\section{Bone marrow findings}

Bone marrow aspiration and biopsy specimens were analyzed to identify sea-blue histiocytes (Niemann-Pick cells) with May-Grümwald-Giemsa staining and foamy cells with hematoxilin-eosin staining.

\section{Filipin test}

Skin biopsy samples were used for fibroblast cultures, and cells were stained for histological examination. The presence of intracellular lipid accumulation was identified with filipin staining; in the 'classical' cholesterol storage pattern, positive cells are typically strongly fluorescent (cholesterol-filled perinuclear vesicles). The pattern of the cell samples was categorized with filipin staining as either normal (clear negative fluorescence); atypical or "variant" (moderated fluorescence); or typical or "classical" (high fluorescence).

\section{Molecular analysis}

Blood samples from the patients were used to isolate DNA by standard method. Coding sequences and flanking regions of the NPC1 and the NPC2 genes were amplified with PCR, purified and submitted to direct DNA sequencing using the BigDye ${ }^{\mathbb{B}}$ Terminator Cycle Sequencing kit v. 3.1 (Applied Biosystems, Foster City, CA, USA) following the manufacturer's instructions. Products were then submitted to capillary electrophoresis in an ABI PRISM ${ }^{\mathbb{R}}$ 3130xl Genetic Analyzer, and sequences were analyzed with DNA Sequencing Analysis software v. 5.2 (Applied Biosystems). Mutations were confirmed by sequencing an independent DNA sample with both forward and reverse primers.

\section{RESULTS}

The report includes five patients (four females and one male) aged 8 to 26 years. The time of disease progression ranged from 2 to 16 years, with a mean time of 6 years. Family members with the same disease were not found. The age at onset of the disease was early infantile in one patient, late infantile in one patients and juvenile in three patients (Table).

All patients had dementia, dystonia, cerebellar ataxia, dysarthria and vertical supranuclear gaze palsy. Other reported clinical features included the following: psychiatric disorders (4/5), epilepsy (2/5), dysphagia (4/5), dysphonia (4/5), weakness (4/5), hepatosplenomegaly (3/5), cataplexy (2/5), cholestasis (1/5) and deafness (1/5) (Table).

Brain MRI was performed for all patients (Table). Diffuse cerebral and cerebellar atrophy was observed in three patients, while two patients had normal imaging results. Mild multifocal areas of hypersignal in the cerebral white matter were observed in one patient (Case 1).

Serum chitotriosidase activity was measured in 4 patients (Table). Serum chitotriosidase levels were above normal limits in all patients and varied from 183 to $1477 \mathrm{nmol} / \mathrm{h} / \mathrm{ml}$ (mean level of $547.75 \mathrm{nmol} / \mathrm{h} / \mathrm{ml}$ ). 


\begin{tabular}{|c|c|c|c|c|c|}
\hline Case & 1 & 2 & 3 & 4 & 5 \\
\hline Gender & $\mathrm{F}$ & $\mathrm{F}$ & $\mathrm{F}$ & $\mathrm{F}$ & M \\
\hline Age at onset (years) & 1 & 12 & 8 & 5 & 14 \\
\hline Age at diagnosis (years) & 8 & 14 & 14 & 9 & 26 \\
\hline Age at last exam (years) & 24 & 21 & 16 & 13 & 30 \\
\hline \multicolumn{6}{|l|}{ Neurological manifestations: } \\
\hline Delayed early development & + & + & - & + & - \\
\hline Psychiatric disorders & + & + & + & - & + \\
\hline Epilepsy & - & + & - & + & - \\
\hline Dementia & + & + & + & + & + \\
\hline Dystonia & + & + & + & + & + \\
\hline Cerebellar ataxia & + & + & + & + & + \\
\hline Dysarthria & + & + & + & + & + \\
\hline Dysphagia & + & + & + & + & - \\
\hline Dysphonia & + & + & + & + & - \\
\hline Weakness & + & + & + & + & - \\
\hline Vertical supranuclear gaze palsy & + & + & + & + & + \\
\hline Deafness & + & - & - & - & - \\
\hline Cataplexy & - & + & + & - & - \\
\hline \multicolumn{6}{|l|}{ Visceral manifestation: } \\
\hline Hepatosplenomegaly & + & - & + & - & + \\
\hline Cholestasis & - & - & + & - & - \\
\hline \multicolumn{6}{|l|}{ Diagnostic tests: } \\
\hline Abnormal brain MRI & + & + & + & - & - \\
\hline High chitotriosidase level & + & + & + & ND & + \\
\hline Sea-blue histiocytes at bone marrow & + & + & + & ND & - \\
\hline Foamy cells at bone marrow & + & + & + & ND & - \\
\hline Filipin staining* & \pm & \pm & + & \pm & + \\
\hline \multicolumn{6}{|l|}{ Molecular analysis: NPC1 gene } \\
\hline Allele 1 & P1007A & P1007A & A764V & P1007A & S954L \\
\hline Allele 2 & P1007A & P1007A & A1035V & A1035V & P887L \\
\hline \multicolumn{6}{|l|}{ Treatment response: } \\
\hline Miglustat & - & - & - & + & ND \\
\hline \multicolumn{6}{|l|}{ Disease progression: } \\
\hline Duration after diagnosis (years) & 16 & 7 & 2 & 4 & 4 \\
\hline Disability scale score at diagnosis & 8 & 12 & 15 & 9 & 7 \\
\hline Disability scale score at last follow-up & 14 & 18 & 16 & 7 & 8 \\
\hline Death & - & - & + & - & - \\
\hline
\end{tabular}

NPC: Newman-Pick disease type C; F: female; M: male; +: present or typical; \pm : atypical; -: absent or negative; ND: not done; MRI: magnetic resonance imaging;

${ }^{*}$ Cells of the fibroblast culture (skin biopsy) show the presence of intracellular lipid accumulation.

Bone marrow specimens were analyzed in 4 patients (Table). Sea-blue histiocytes and foamy cells were identified in three patients (Figures D, E and F).

Skin fibroblast culture was performed for all patients (Table). The cell patterns from the filipin stains were classified as atypical in three patients and typical in two patients (Figures A,B and C).

Molecular analysis was performed in all patients (Table). Mutations in NPC1 gene were found in all alleles. Two patients were homozygotes for the p.P1007A mutation, and compound heterozygotic mutations (p.P1007A, p.A1035V, p.A764V, p.S954L and p.P887L) were found in three patients.

Substrate reduction therapy with miglustat (600 mg/day) was administered to 4 patients (Table). The treatment response was clearly beneficial in at least one case (Case
4). The miglustat dosage was decreased (to $200 \mathrm{mg} /$ day) due to the occurrence of gastrointestinal side effects in one patient (Case 2).

Disease follow-up after diagnosis ranged from 2 to 16 years with a mean time of 6.6 years. NP-C-specific disability scale scores ranged from 7 to 15 (mean: 10.2) at disease diagnosis and from 7 to 18 (mean: 12.6) at final follow-up. One patient died during the treatment due to pneumonia (Case 3).

\section{DISCUSSION}

Although specific clinical features vary, some main core features were present in all of our patients. Vertical supranuclear gaze palsy has been included as a clinical criterion 

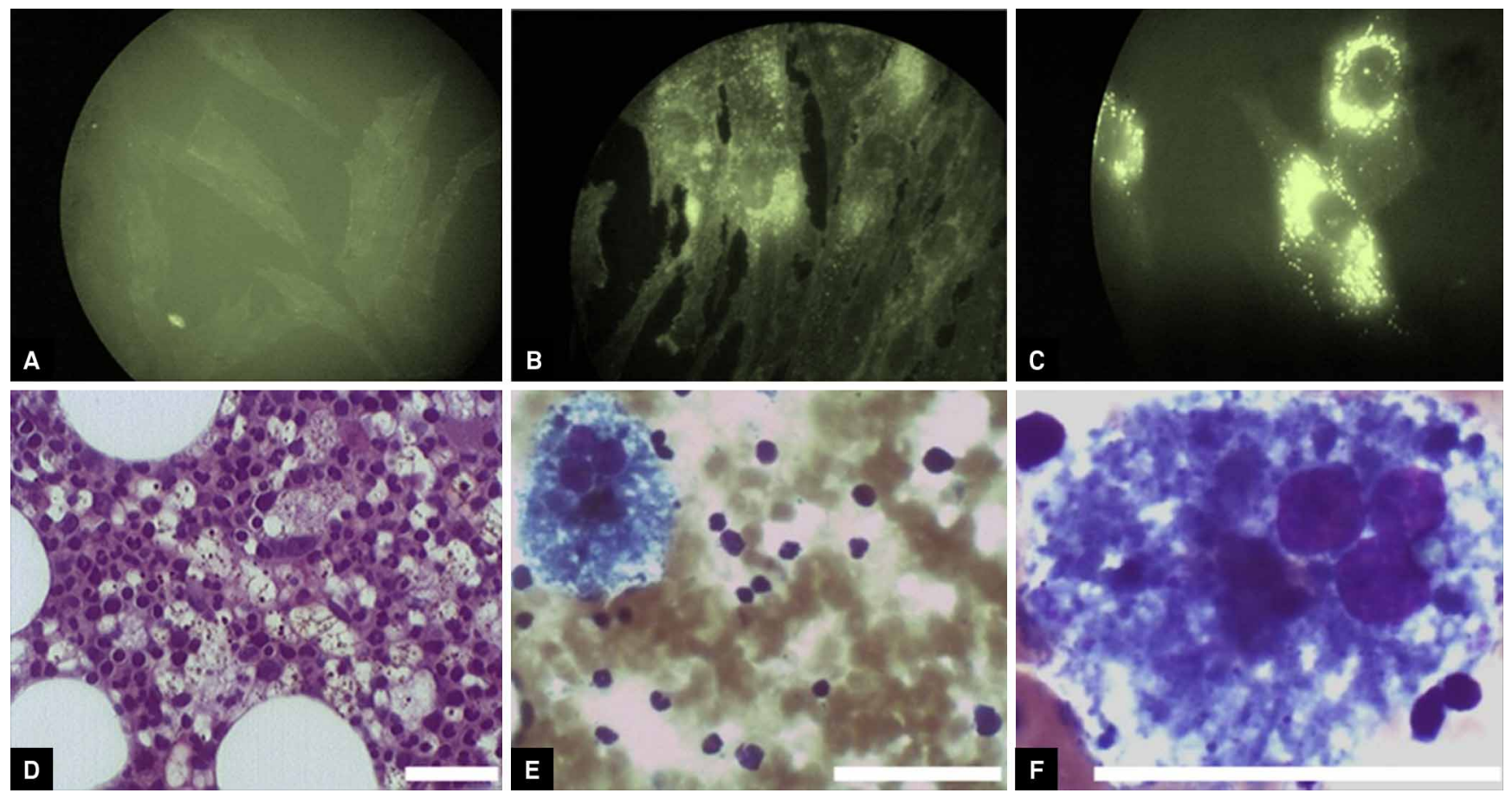

Figure. Cells of the fibroblast culture (skin biopsy) showed the presence of intracellular lipid accumulation observed with filipin staining: normal control with clear negative fluorescence (A); "variant" pattern with moderated fluorescence in Case 2 (B); and "classical" pattern with cholesterol-filled perinuclear vesicles typically strongly fluorescent in Case 3 (C); bone marrow biopsy showing foamy cells with hematoxilin-eosin staining in Case 1 (D); bone marrow aspiration reveals sea blue histiocites with MayGrümwald-Giemsa staining, or Niemann-Pick cells in Case 3 (E, F). Bar=50um.

or core feature of NP-C $\mathrm{C}^{2,4,5}$. This criterion may be an important clinical feature, which can help to identify the disease in patients with cerebellar ataxia, dystonia or dementia ${ }^{2,7}$.

Brain MRI generally reveals cerebellar atrophy that can be associated with cerebral atrophy or unspecific abnormalities of cerebral white-matter ${ }^{7,8}$. Brain MRI is important for initial screening and differential diagnoses of other causes of cerebellar ataxia, epilepsy and dementia, but the findings are not specific for the NP-C diagnosis. In addition, high serum chitotriosidase levels were useful as an initial screening for our patients, but this enzyme is not a specific marker for NP-C $\mathrm{C}^{4}$. Other assessments are necessary for disease diagnosis.

Diagnostic investigation revealed abnormal cell patterns after filipin staining in all patients, but the typical pattern was found in only two patients. The presence of an atypical pattern after filipin staining is associated with specific mutations of the NPCl gene ${ }^{4}$. The three cases presenting an atypical pattern after filipin staining all presented with the $\mathrm{p}$. P1007A mutation. Our findings help to confirm previous reports suggesting that the p.P1007A mutation can show atypical or "variant" findings with filipin staining8. We believe that in these cases, bone marrow analysis can be useful for NP-C diagnosis because the presence of sea-blue histiocytes and foamy cells was similar for all of our cases ${ }^{6,7}$. Although sea-blue histiocytes are not pathognomonic of NP-C. The typical pattern of filipin staining was found for two patients and was important for the case with a new mutation (p.A764V) of the NPC1 gene to confirm that this was a pathogenic mutation. We believe that fibroblast culture to filipin staining is a technically complex procedure. We suggest that, in the future, this procedure should be used only to confirm the pathogenic character of a new mutation after molecular analysis. Therefore, filipin staining of the bone marrow cells can be used to provide a rapid screening test for NP-C, but it is not considered to be a definitive diagnostic method 6 .

Several mutations of the $\mathrm{NPCl}$ gene have been described in NP-C patients ${ }^{8-10}$. The p.P1007A mutation of the NPC1 gene is frequently reported to cause, mainly juvenile or adult forms, of the disease in several countries ${ }^{8,9}$. In our study in Brazil, only a few patients with molecular analysis results available were described, and it is not possible to conclude what is the most common mutation in this population ${ }^{7,11}$. The p.P1007A and p.A1035V mutations were previously reported in Brazil, and our study contributes to the idea that they are frequent $N P C 1$ mutations in this country although only a few patients were analyzed ${ }^{7,11}$.

Treatment response can be evaluated with the NP-C-specific disability scale during treatment ${ }^{2,6,12-14}$. In our patients, a clear beneficial response was observed in one case. We should note that disability scores at diagnosis were already high in cases which did not show observed beneficial response, which could have contributed to our results, as 
miglustat is less likely to provide substantial therapeutic benefits if severe neurological impairment is already present at diagnosis ${ }^{4,6,12-14}$. In these cases, decisions to start treatment should be on a case-by-case basis ${ }^{4,6,12}$. Comparisons between disability scores at diagnosis and treatment response in our study agree with the classical clinical opinion that treatment response is better in patients with mild neurological disability ${ }^{4,6,13}$. As most of our patients had early onset of the disease, this circumstance could have influenced our findings as well, as treatment response is correlated with the age at onset, with adult onset being less disabling than infantile onset ${ }^{4,6,13,14}$. To make available the diagnostic toolkits that are needed to provide earlier diagnosis is important goal in Brazil to obtain better treatment results for NP-C patients.

\section{Acknowledgements}

Professor Mariester Malvezzi (Hematology Service, HC, UFPR) for their collaboration in the bone marrow analysis. Bárbara Silveira, Suellen Melo and Evelize Bonh (Medical Genetics Service, HCPA) for their collaboration with the fibroblast culture and filipin staining process.

\section{References}

1. Wraith E, Guffon N, Rohrbach M, et al. Natural history of Niemann-Pick disease type $C$ in a multicentre observational retrospective cohort study. Mol Genet Metab 2009;98:250-254.

2. Patterson MC, Mengel E, Wijburg FA, et al. Disease and patient characteristics in NP-C patients: findings from an international disease registry. Orphanet J Rare Dis 2013;8:12

3. Iturriaga C, Pineda M, Fernández-Valero EM, Vanier MT, Coll MJ. Niemann-Pick $C$ disease in Spain: clinical spectrum and development of a disability scale. J Neurol Sci 2006;249:1-6.

4. Wraith JE, Baumgartner MR, Bembi B, et al. Recommendations on the diagnosis and management of Niemann-Pick disease type C. Mol Genet Metab 2009;98:152-165.

5. Vanier MT. Niemann-Pick disease type C. Orphanet J Rare Dis 2010;5:16.

6. Patterson MC, Hendriksz CJ, Walterfang M, Sedel F, Vanier MT, Wijburg F. Recommendations for the diagnosis and management of Niemann-Pick disease type C: an update. Mol Genet Metab 2012;106:330-344.

7. Godeiro-Júnior C, Inaoka RJ, Barbosa MR, Silva MR, Aguiar PC, Barsottini O. Mutations in NPC1 in two Brazilian patients with Niemann-Pick disease type $C$ and progressive supranuclear palsylike presentation. Mov Disord 2006;21:2270-2272.
8. Macías-Vidal J, Rodríguez-Pascau L, Sanchez-Olle G, et al. Molecular analysis of 30 Niemann-Pick type C patients from Spain. Clin Genet 2011;80:39-49.

9. Millat G, Bailo N, Molinero S, Rodriguez C, Chikh K, Vanier MT. Niemann-Pick $C$ disease: use of denaturing high performance liquid chromatography for the detection of NPC1 and NPC2 genetic variations and impact on management of patients and families. Mol Genet Metab 2005;86:220-232.

10. Fancello T, Dardis A, Rosano C, et al. Molecular analysis of NPC1 and NPC2 gene in 34 Niemann-Pick C Italian patients: identification and structural modeling of novel mutations. Neurogenetics 2009;10:229-239.

11. Pedroso JL, Fusão EF, Ladeia-Frota C, et al. Teaching video neuroimages: gelastic cataplexy as the first neurologic manifestation of Niemann-Pick disease type C. Neurology 2012;79:189.

12. Pérez-Poyato MS, Gordo MM, Marfa MP. Initiation and discontinuation of substrate inhibitor treatment in patients with Niemann-Pick type C disease. Gene 2012;506:207-210.

13. Pineda M, Wraith JE, Mengel E, et al. Miglustat in patients with Niemann-Pick disease type C (NP-C): a multicenter observational retrospective cohort study. Mol Genet Metab 2009;98:243-249.

14. Pineda M, Perez-Poyato MS, O’Callaghan M, et al. Clinical experience with miglustat therapy in pediatric patients with Niemann-Pick disease type C: a case series. Mol Genet Metab 2010;99:358-366. 